\title{
Larval Development of Mosquitoes and pH of Different Reservoirs in the City of Cartagena de Indias (Colombia)
}

\author{
Diego F. Tirado ${ }^{\& 1}$, Edilber Almanza-Vasquez ${ }^{\# 2}$, Edilber J. Almanza-Meza ${ }^{* 3}$, Diofanor Acevedo- \\ Correa $^{\$ 4}$, Kevin J. González-Morelo $\$ 5$ \\ ${ }^{\&}$ Department of Chemical Engineering, School of Chemistry, Universidad Complutense de Madrid, Av. \\ Complutense s/n, 28020, Madrid, Spain. \\ \#Department of Mathematics, School of Exact and Natural Sciences, Campus of San Pablo, Universidad de \\ Cartagena, Cartagena de Indias, Colombia. \\ *Department of Medicine, School of Medicine, Medicine program, Universidad de Cartagena, Campus of \\ Zaragocilla, Cartagena de Indias, Colombia. \\ ${ }^{\$}$ Research Group Nutrición, Salud y Calidad Alimentaria (NUSCA), Universidad de Cartagena, Campus of \\ Piedra de Bolívar, Cartagena de Indias, Colombia. \\ 1ditirado@ucm.es, 2ealmanzav@unicartagena.edu.co, ${ }^{3}$ edilberjose@hotmail.com, ${ }^{4}$ diofanor3000@gmail.com, \\ 5kevinjgonza@hotmail.com.
}

\begin{abstract}
This study aimed to determine the effect of water pH on the development of larvae of Aedes aegypti, Anopheles albimanus and Culex mosquitoes. Quarterly samplings from March 2012 until June 2013 were made. Mosquito larvae in three different zones of the city of Cartagena de Indias (Colombia) were collected and classified. The water where those were deposited, it was acidified with lemon juice and alkalized with sodium bicarbonate. The larvae were fed with poultry feed once a day during its development. The larvae of $A$. albimanus and Culex were better adapted in acidic media and those of $A$. aegypti in basic media. The ideal $\mathrm{pH}$ for larval growth was between 6.5 and 7.5.
\end{abstract}

Keyword - pH, Aedes aegypti, Anopheles albimanus, Culex, Mosquito, Larval development.

\section{INTRODUCTION}

Diseases such as dengue, malaria, yellow fever, encephalitis, cholera and leishmaniasis, among others, entirely or partially incapacitate people who suffer from it. Its vectors are effective in reproducing and transporting viruses, without adequate control of them is prone to cause an epidemic. Epidemiology has among its purposes to describe and explain the dynamics of population health, identify the elements that compose it and understand the forces that govern it, to intervene during its natural development. Entomological surveillance is undoubtedly the most critical part of establishing early detection systems to anticipate possible arboviral diseases [1]. The study of mosquitoes transmitting vectors of dengue fever and yellow fever (Aedes aegypti), malaria (Anopheles albimanus) and viral encephalitis and West Nile fever (Culex) is a priority for reducing the risk of contracting them, through actions that increase environmental safety and reduce contact with vectors [1], [2].

Malaria is the most important parasitic disease for global health; it is caused by one of the five species of the Plasmodium genus: $P$. falciparum, $P$. vivax, $P$. ovale, $P$. malariae and recently described the effect of $P$. knowlesi as a causal agent of malaria infection in humans [3]. Historically, malaria has been responsible for the deaths of more people than any other parasitic disease and still has high rates of morbidity and mortality [4]. It is estimated that more than 2.7 million people, mainly children, die from malaria each year, and a population of more than 2 billion lives in endemic malaria regions [5].

Dengue fever is currently the most important arbovirus disease in humans, with an estimated between 50 and 100 million cases of dengue fever annually and between 250000 and 500000 cases of its most severe forms, dengue hemorrhagic fever and dengue shock syndrome. Nearly four million people are at risk in 128 countries worldwide [6]. A. aegypti is the primary vector of dengue and other diseases such as chikungunya and yellow fever [7]. However, current control interventions are not sufficiently efficient or sustainable, and more costeffective strategies are needed [2], [8]-[10].

Other authors have been commissioned to study the incidence of factors in larval growth [1], [2], [11], [12], finding that control mechanisms may exist for these factors, and thus be able to reduce biological risk. The identification of critical points, suitable for directing immediate control actions, can be a way to make control 
programs more efficient [11], [12]. Spatial propitiators may be exogenous, such as $\mathrm{pH}$, generated by factors or processes that are not directly related to the variable under study [2].

The lifespan of adult mosquitoes is affected by climatic conditions, mainly humidity and temperature, as they condition its feeding, reproduction and resting activities. During the rainy season, densities increase as a result of the availability of more nurseries [13]. Currently, it is necessary to use new vector control techniques at all stages in order to ensure the efficiency of the methods, while minimizing undesirable effects on the environment and public health. Spatial analysis has gained an important role in epidemiology in the last two decades [14]; therefore this study analysed the effect of water $\mathrm{pH}$ on the development of larvae of Aedes aegypti, Anopheles albimanus and Culex mosquitoes to identify its importance as an external factor in larval growth.

\section{Materials AND Methods}

This paper corresponds to a cross-sectional, descriptive and observational study, such as other authors have done in the past in similar studies [15]-[17]. The observation units correspond to the number of larvae that pupate at each $\mathrm{pH}$ level of the habitat. A. albimanus larvae were collected in the Colombiatón neighbourhood, Culex and A. aegypti in the Cielo Mar neighbourhood. Both neighbourhoods were located in Cartagena de Indias (Colombia). The water where they were deposited was acidified with lemon juice and alkalinised with sodium bicarbonate. An LCD digital $\mathrm{pH}$ meter was used for $\mathrm{pH}$ measurement.

Larvae were collected in March 2012, June 2012, September 2012, December 2012, March 2013 and June 2013 between 6:00 AM and 7:00 AM. In the laboratory, the larvae were separated and counted, keeping $250 \mathrm{~mL}$ of water in glass containers. In each of them, between 20 and 40 mosquito larvae were added, being September and March when the most significant number of larvae were found. Each container had water with controlled $\mathrm{pH}$ from 4.5 to 10.5 . The larvae were fed in the morning with chicken concentrate. The initial time in each case was the moment when the mosquito larvae were transferred to the vessels with different $\mathrm{pH}$. From that moment on, the mosquito larvae were counted in each of the containers every $24 \mathrm{~h}$. Then the amount that had passed into its next phase was calculated. The determinations were made by triplicate, and the results were expressed as the mean \pm standard deviation. For this, Statgraphics Centurion XVI statistical package (Statgraphics Centurion Version 16.1.15, Chicago, EE. UU) was used [18]. The mean and standard deviation of the results were calculated in the analyses performed. The t-student test was applied for data analysis. The significance level was set at $\mathrm{p}<0.05$.

\section{III.RESULTS AND DISCUSSIONS}

Fig. 1 shows the larvae index at different $\mathrm{pH}$. From the results, it can be seen that at $\mathrm{pH}$ of 4.5 , the development of $A$. aegypti larvae was more affected than A. albimanus larvae $(\mathrm{p}<0.05)$. Culex and $A$. albimanus larvae did not survive at $\mathrm{pH} 10.5$, while almost $25 \%$ of $A$. aegypti larvae passed into their adult state under the same conditions.

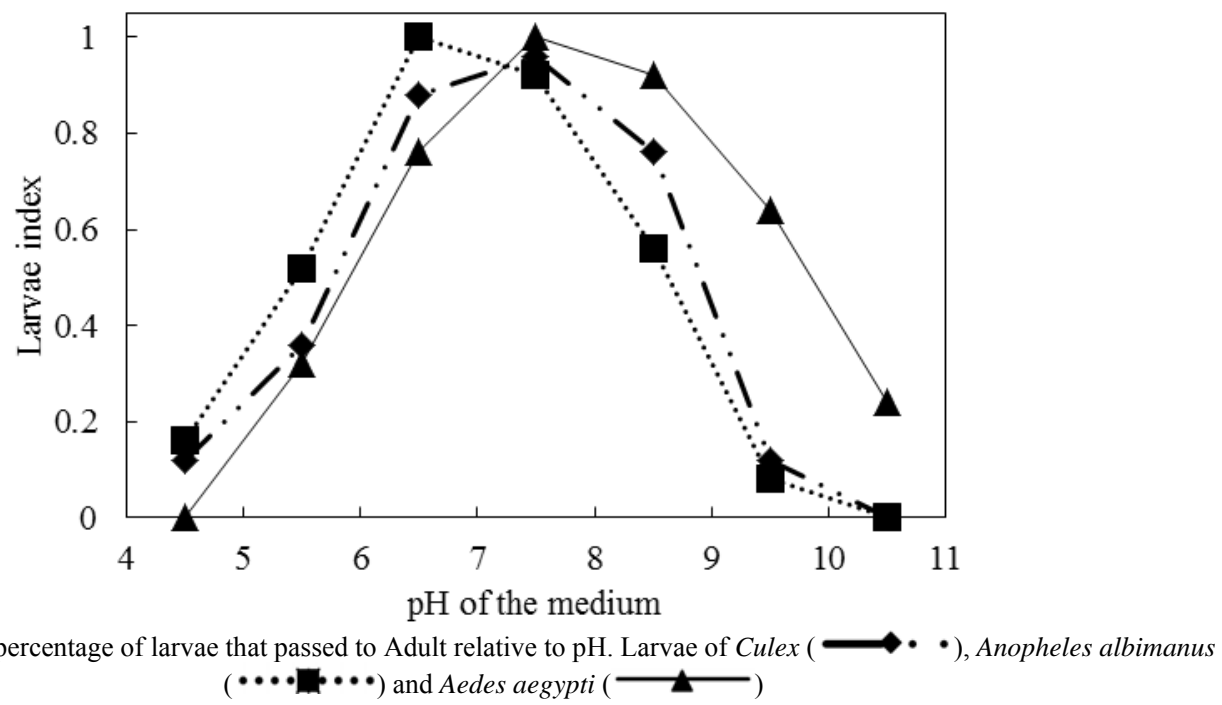

The ideal $\mathrm{pH}$ for the development of A. albimanus larvae was around 6.5, meanwhile, for A. aegypti larvae it was around 7.5 and between 6.5 and 7.5 for Culex larvae. Furthermore, during the rainy periods (between September and March) the highest amount of embryonic development occurred in the city of Cartagena de Indias. In this city, the highest number of cases of dengue fever happens in the first and third semesters of each 
year according to DADIS [19]. In Cartagena, mosquito classes are found in areas of different socioeconomic strata, as reported by other authors in other tropical cities [1]. Similar results were obtained in the study reported by Honório et al., [15], who conducted a longitudinal entomological survey with weekly egg collections in three neighbourhoods of Rio de Janeiro, Brazil, between September 2006 and March 2008 to determine the association between the meteorological and mosquito density variables, measured by ovitramps and sticky traps. The authors demonstrated that the mosquito density was positively and nonlinearly linked to the mean air temperature in three neighbourhoods. This reflects the importance of having external factors $(\mathrm{pH}$, temperature, among others) in the growth of the larvae studied [1].

\section{IV.CONCLUSIONS}

By analysing spatial patterns of disease incidence and/or vector emergence and abundance could provide insight into the processes that determine disease risk and to identify areas where control actions are most needed. The larval index of mosquitoes as a risk factor for disease development and as an entomological indicator should be taken into account in epidemiological surveillance actions in the city. Adequate control must be maintained at all stages of the vectors. Vector control must be integral, combining the different types of methods with rationality, safety, efficacy, adaptability and acceptability criteria, aimed at the stages of the life cycle of the vectors.

\section{REFERENCES}

[1] H. M. Yang, M. L. G. Macoris, K. C. Galvani, M. T. M. Andrighetti, and D. M. V. Wanderley, "Assessing the effects of temperature on the population of Aedes aegypti, the vector of dengue," Epidemiol. Infect., vol. 137, no. 8, p. 1188, Aug. 2009.

[2] F. M. Garelli, M. O. Espinosa, D. Weinberg, M. A. Trinelli, and R. E. Gürtler, "Water Use Practices Limit the Effectiveness of a Temephos-Based Aedes aegypti Larval Control Program in Northern Argentina," PLoS Negl. Trop. Dis., vol. 5, no. 3, p. e991, Mar. 2011.

[3] B. Singh et al., "A large focus of naturally acquired Plasmodium knowlesi infections in human beings," Lancet, vol. 363, no. 9414, pp. 1017-1024, Mar. 2004

[4] R. Tuteja, "Introduction: Malaria - the global disease," FEBS J., vol. 274, no. 18, pp. 4669-4669, Sep. 2007.

[5] S. I. Hay, C. A. Guerra, A. J. Tatem, A. M. Noor, and R. W. Snow, "The global distribution and population at risk of malaria: past, present, and future," Lancet Infect. Dis., vol. 4, no. 6, pp. 327-336, Jun. 2004.

[6] O. J. Brady et al., "Refining the Global Spatial Limits of Dengue Virus Transmission by Evidence-Based Consensus," PLoS Negl. Trop. Dis., vol. 6, no. 8, p. e1760, Aug. 2012.

[7] P. Posada, Y. Ferrer, and I. Rodríguez, "El vector Aedes aegypti durante la epidemia de dengue en Ciego de Ávila.," MEDICIEGO, vol. 16, no. 1, pp. 1-7, 2010.

[8] Y. A. Halasa, B. Zambrano, D. S. Shepard, G. H. Dayan, and L. Coudeville, "Economic Impact of Dengue Illness in the Americas," Am. J. Trop. Med. Hyg., vol. 84, no. 2, pp. 200-207, Feb. 2011.

[9] J. A. Potts et al., "Prediction of Dengue Disease Severity among Pediatric Thai Patients Using Early Clinical Laboratory Indicators," PLoS Negl. Trop. Dis., vol. 4, no. 8, p. e769, Aug. 2010.

[10] M. Carrazana, M. D. C. Marquetti, A. Vásquez, and J. L. Montes de Oca, "Dinámica estacional y temporal de Aedes aegypti (Diptera: Culicidae) en el municipio Cienfuegos," Rev. Cubana Med. Trop., vol. 62, no. 2, pp. 98-106, 2010.

[11] R. Barrera, "Spatial Stability of Adult Aedes aegypti Populations," Am. J. Trop. Med. Hyg., vol. 85, no. 6, pp. 1087-1092, Dec. 2011.

[12] T. Bousema et al., "Hitting Hotspots: Spatial Targeting of Malaria for Control and Elimination," PLoS Med., vol. 9, no. 1, p. e1001165, Jan. 2012.

[13] M. H. Badii, J. Landeros, E. Cerna, and J. L. Abreu, “Ecología e historia del dengue en las Américas,” Int. J. Good Conscienc., vol. 2, no. 2, pp. 248-273, 2007.

[14] A. H. Auchincloss, S. Y. Gebreab, C. Mair, and A. V. Diez Roux, “A Review of Spatial Methods in Epidemiology, 2000-2010,” Annu. Rev. Public Health, vol. 33, no. 1, pp. 107-122, Apr. 2012.

[15] N. A. Honório, W. da C. Silva, P. J. Leite, J. M. Gonçalves, L. P. Lounibos, and R. Lourenço-de-Oliveira, "Dispersal of Aedes aegypti and Aedes albopictus (Diptera: Culicidae) in an urban endemic dengue area in the State of Rio de Janeiro, Brazil," Mem. Inst. Oswaldo Cruz, vol. 98, no. 2, pp. 191-198, Mar. 2003.

[16] R. González, "Efecto del criadero sobre la duración del ciclo de vida y productividad de Anopheles albimanus Wiedemann (Diptera: Culicidae)," Boletín del Mus. Entomológico la Univ. del Val., vol. 6, no. 1, pp. 1-6, 2005.

[17] J. A. Bisset Lazcano, M. D. C. Marquetti, R. Portillo, M. M. Rodríguez, S. Suárez, and M. Leyva, "Factores ecológicos asociados con la presencia de larvas de Aedes aegypti en zonas de alta infestación del municipio Playa, Ciudad de La Habana, Cuba,” Rev. Panam. Salud Pública, vol. 19, no. 6, pp. 379-384, 2006.

[18] Statgraphics, "Statpgraphics Centurion Statpoint technologies Inc." 2009.

[19] DADIS, “Información estadística indicadores de salud pública 2012,” Departamento Administrativo Distrital de Salud, 2013. [Online]. Available: http://www.dadiscartagena.gov.co/images/docs/saludpublica/vigilancia/comovamos/cartagena_como_vamos_salud_publica.pdf. .

\section{AUTHOR PROFILE}

Diego F. Tirado is a $\mathrm{PhD}$ student in Chemical Engineering at the Universidad Complutense de Madrid (Spain). Mr. Tirado has a bachelor degree in Food Engineering and a master degree in Environmental Engineering from the Universidad de Cartagena (Colombia). 
Edilber Almanza-Vasquez works as a full-time professor at the Universidad de Cartagena. Mr. Almanza is a Mathematician from the Universidad de Sucre (Colombia) and he has a master degree in Biomathematics from the Universidad del Quindío (Colombia).

Edilber J. Almanza-Meza is a doctor from the Universidad de Cartagena.

Diofanor Acevedo-Correa works as a full-time professor at the Universidad de Cartagena. Dr. Acevedo has a doctoral degree in Food Engineering from the Universidad del Valle (Colombia). He has bachelor degrees in Food Engineering and Pharmaceutical Chemistry from the Universidad de Cartagena. Furthermore, he is a fulltime researcher of the Research Group Nutrición, Salud y Calidad Alimentaria (NUSCA).

Kevin José González-Morelo works as a research assistant in the Research Group NUSCA and has a bachelor degree in Food Engineering from the Universidad de Cartagena. 